\title{
Orquestrando processos didáticos com Design Thinking
}

\author{
Paulo André da Silva ${ }^{1}$; Patrícia Smith Cavalcante ${ }^{2}$ \\ ${ }^{1}$ Programa de Pós Graduação em Educação Matemática e Tecnológica - EDUMATEC \\ Universidade Federal de Pernambuco (UFPE) - Recife- PE - Brasil. \\ ${ }^{2}$ Programa de Pós Graduação em Educação Matemática e Tecnológica - EDUMATEC \\ Universidade Federal de Pernambuco (UFPE) - Recife- PE - Brasil. \\ profe.pas@gmail.com; patricia.cavalcante@ufpe.br
}

\begin{abstract}
The required breakdown of teaching-learning paradigms drives the critical use of digital artifacts (and not digital). Associating design thinking techniques for planning purposes of educational activities, we used a didactic structure that dialogues with ideas coming from the pedagogical architecture and the concept of teaching process orchestration for learning. We aimed to prepare students from undergraduate to critical and practical use of digital artifacts in classroom interaction processes and a distance too, creating planning actions for their own training.
\end{abstract}

Keywords: Orchestration; planning; design thinking; digital artifacts

Resumo. A necessária quebra de paradigmas de ensino-aprendizagem impulsiona o uso crítico de artefatos digitais (e não digitais). Associando técnicas de design thinking para fins de planejamento de atividades pedagógicas, lançamos mão de uma estrutura didática que dialoga com ideias oriundas da arquitetura pedagógica $e$ do conceito de orquestração de processos de ensino para a aprendizagem. Objetivamos preparar graduandos da licenciatura para uso crítico e prático de artefatos digitais em processos de interação presencial e a distância, criando planejamento de ações para sua própria formação.

Palavras chave: Orquestração; planejamento; design thinking; artefatos digitais. 
V Congresso Brasileiro de Informática na Educação (CBIE 2016)

Anais dos Workshops do V Congresso Brasileiro de Informática na Educação (CBIE 2016)

\title{
1. Introdução
}

O contexto cultural do século XXI é marcado pela tecnologização dos meios de comunicação e, consequentemente, levanta aspectos de proliferação de ideias e produtos que são rapidamente difundidos e consumidos pelos usuários das mídias sociais. Estabelece assim a formação ou consolidação de uma (nova) cultura digital, a qual apresenta modelos próprios de se compreender e viver na sociedade atual.

Neste contexto da cultura digital, seria no mínimo inocência pensar que a quantidade e alcance das informações e a aproximação a todo um aparato tecnológico presente no cotidiano das pessoas, não alterem a nossa forma de olhar e viver este mundo. Alteram nossa percepção do meio, nossa maneira de dialogar, de se relacionar, de trabalhar, de estudar, enfim, de fazer nossas atividades diárias. Se concordamos que essas relações são alteradas e que ainda estão em movimento, precisamos nos questionar sobre quais competências e habilidades precisamos desenvolver para que consigamos viver neste "novo mundo" de forma equilibrada e saudável.

\begin{abstract}
A relação Homem e tecnologia é histórica, e sempre esteve no foco de nossas atenções, visto que isto perdura por toda a existência humana. Mas no caso da tecnologia digital, não se pode deixar de notar a profunda alteração no modo de ser do Homem frente aos outros e a si mesmo graças ao que as novas tecnologias permitem fazer [Viana 2005 p. 12].
\end{abstract}

Compreendemos que a formação de futuros professores deve buscar compreensão sobre as propriedades ou características que compõem a estrutura dos artefatos digitais, de forma a promover processos de ensino-aprendizagem que dialoguem com interesses dos estudantes, em um sentido social, de aplicação de conceitos científicos para vida. Associando a esta compreensão dos artefatos digitais, unificamos a ideia de empoderamento dos estudantes para que pensem, façam e excutem o planejamento de uma disciplina, a partir de uma corresponsabilização do processo com o próprio docente [Gomes e Silva 2016]. Tal ação permite que sejam exploradas novas formas do fazer educacional na graduação, criando novas experiências de aprendizagem e o desenvolvimento ativo da autonomia dos alunos.

Entendemos o sujeito em desenvolvimento e constituído sócio-historicamente, que não se apropria passivamente do seu universo cultural, mas, ao contrário, apropriase dele, ressignificando-o e transformando-o de modo dialético e dinâmico [Vigotsky 1984].

Neste artigo, apresentamos e discutimos uma proposta interacional de ensinoaprendizagem, a partir do uso de diferentes artefatos digitais e não digitais, com suporte presencial e também o uso de uma plataforma social virtual.

Desta forma, visamos a formação dos alunos a partir de um processo de orquestração [Prieto 2010; Fischer and Dillenbourg 2006] que dialoga com a arquitetura pedagógica, em um processo de trabalho quase-artesanal, construído a partir das vivências, das experiências e demandas requeridas pelas próprias ações, interações e reflexões dos sujeitos envolvidos sobre os fatos, os objetos e o meio ambiente sócioecológico ao qual pertencem [Kerckhove 2003]

O suporte teórico da arquitetura pedagógica nos é rico, pois a mesma estabelece a dimensão dialógica de diferentes componentes como: a própria abordagem pedagógica, o uso da Internet, de algum software, de artefatos digitais, da educação a 
distância, da ressignificação de espaço e tempo. Esses elementos, se assim podemos chamar, são imprescindíveis para uma leitura educacional que valoriza as relações pessoais e com o campo do saber para produção do conhecimento. Temos no planejamento nosso ponto de partida e de manutenção do caminho a ser percorrido.

Fazem parte deste processo as dimensões de planejamento e ação docente. No caso do planejamento, utilizamos as ferramentas de design thinking. Para a ação docente, trabalhamos com a teoria da orquestração.

\section{O Planejamento}

Freire (2000, p.118), com aguda simplicidade, afirma que somos indivíduos em constante construção. Segundo ele, "o ser humano é, naturalmente, um ser da intervenção no mundo à razão de que faz a História. Nela, por isso mesmo, deve deixar suas marcas de sujeito e não pegadas de puro objeto".

A intervenção citada por Freire nos remete a reflexão e, podemos dizer, uma constatação de que o homem, na certeza da sua incompletude, da sua finitude, da sua inconclusão como "parte da experiência vital", despertou sua "capacidade de reconhecer-se como tal". Ou seja, cresceu uma consciência de ser inacabado provocando nos indivíduos "um permanente movimento de busca a que se junta, necessariamente, a capacidade de intervenção no mundo" [Freire 2000, p.119/120].

Assim, nasce a exigência de uma forma de controle e domínio sobre suas percepções e vontades de realização, reveladas em eventos futuros, como um modo de antecipar os resultados e efeitos do trabalho a ser produzido, das sementes que foram semeadas, tratadas e colhidas como frutos da e pela ação humana.

Ao longo do tempo e da prática de realizações de subsistência ou de conquistas, o homem sistematiza suas ações, desenvolvendo e tomando posse de conhecimentos técnicos mais específicos e eficazes para execução das suas atividades. Essa diferenciação técnica, sistemática, intencional e consciente é o que diferencia os homens dos demais animais, além de estabelecer um modelo de relacionamento com as outras pessoas.

É nesta ação de busca por previsão do real, que o homem exerce o planejamento, entendido aqui enquanto um processo que requer graus diferenciados de organização, previsão, sistematização, decisão, comunicação, diálogo e especialmente reflexão sobre o que se quer e se faz, no próprio processo de desenvolvimento do planejado, que corroborem para garantir a eficiência e eficácia de uma determinada ação, quer seja para um projeto curto ou mais simples (nível micro), quer seja para um projeto mais amplo, complexo (nível macro) [Gomes e Silva 2016].

Podemos resumir aqui, dizendo simplesmente que o planejamento é um exercício mental rebuscado que tem sua origem desde os primórdios humanos, como ações de trabalho e que com o tempo foi se sofisticando, agregando conceitos filosóficos e científicos e tornando-se em si mesmo um conceito.

Compreender o processo de planejamento considerando o conjunto do status social, político e psicológico que envolve ambientes de ensino e consequentemente o fazer didático, nos remete a necessidade de situar o planejamento enquanto uma 
abertura para se pensar o fazer educacional, o trabalho pedagógico na sua complexidade. Isto é, estabelecer um processo de reflexão em busca de significados para aquilo que se propõe realizar. Adequando assim o trabalho docente a uma função educacional intencional de formação de cidadãos, de formação de valores que nutram positivamente a sociedade.

No que tange a sua dimensão mais prática, pensamos em modelos de planejamento que facilitem o olhar do professor sobre seus planos de ensino. Tais modelos, inspirados em técnicas de design - design thinking [Vianna et al 2012] podem concretizar, através de ferramentas específicas e contextualizadas, o trabalho do professor na sua ação de planejamento.

\begin{abstract}
O design thinking traz uma visão holística para a inovação. São equipes multidisciplinares que seguem um processo, entendendo os consumidores, funcionários e fornecedores no contexto onde se encontram, cocriando com os especialistas as soluções e prototipando para entender melhor as suas necessidades, gerando ao final novas soluções, geralmente inusitadas e inovadoras [Vianna et al 2012, p. 7].
\end{abstract}

Apesar de o design thinking ser pensado e aplicado em um contexto empresarial, propomos o uso de algumas de suas ideias, pois entendemos que as mesmas podem colaborar para o processo de planejamento no contexto das Instituições de Ensino (IE).

Técnicas como o uso de mapas de registro (canvas) são exemplos de possibilidades visuais no ato do planejamento. Além disto, ainda se propõe ações de imersão através de pesquisa e de sensibilização individual, unificando com ações de análise e crítica sobre a prática didática, para então partirmos para ações de ideação e prototipação dos planos a serem executados.

Entendemos ainda que apenas o fato de aplicar técnicas de design específicas para planejamento de aulas não é suficiente para o que professor as execute com o mesmo grau de qualidade que desenvolveu seus planos. Assim vislumbramos na orquestração [Dimitriadis 2010; Dilembourg 2013] uma possível alternativa que ajude o professor no gerenciamento da sua prática, ainda mais quando se agrega recursos computacionais de suporte a aprendizagem.

\title{
3. Orquestração
}

A teoria de orquestração implica, resumidamente, na maneira pela qual o professor gerencia as diferentes atividades educacionais, voltando-se para práticas sociais significativas. Prieto (2010) indica três mecanismos que cooperam para efetivação desse processo: (i) sensibilização, (ii) gestão da classe (aulas) e (iii) adaptação da dinâmica de atividades. Atrelamos a este processo proposto por Pietro a necessidade de um planejamento eficaz. Pautado em recursos tecnológicos e em técnicas de design que agreguem significado para as práticas didáticas a serem vivenciadas ao longo do curso/semestre letivo.

Para Prieto (2010), as múltiplas relações que se estabelecem entre alunos, professores e os objetivos educacionais presentes nos planos elaborados, impulsionam o desenvolvimento de um olhar dinâmico e contínuo sobre o gerenciamento das ações planejadas. Este não é um desafio simples, pois exige uma compreensão mais ampla sobre a própria prática docente, considerando as alternativas de mediação didática e de 
V Congresso Brasileiro de Informática na Educação (CBIE 2016)

Anais dos Workshops do V Congresso Brasileiro de Informática na Educação (CBIE 2016)

uso de ferramentas que deem suporte efetivo a construção e avaliação dos processos didáticos planejados.

Assim, um processo de orquestração se passa essencialmente por uma tomada de consciência sobre os mecanismos que se pretende usar e sobre os processos que estão implicados, requer uso de ferramentas e artefatos digitais (ou não) adequados para a regulação do processo, sendo esta preferencialmente in time, a fim de que o professor possa intervir e gerenciar o fluxo do trabalho, redirecionando as atividades de forma que promova novas formas de se entender o trabalho pedagógico.

Além disso, aliar técnicas comunicacionais, técnicas de design e artefatos digitais ao processo de planejamento e a orquestração deste, podem colaborar para uma ressignificação dos espaços educacionais, potencializando a formação integral dos sujeitos - docentes e discentes.

\section{Metodologia}

Esta pesquisa está sendo desenvolvida como parte de uma pesquisa maior em nível de doutorado, a qual envolverá outros professores do Ensino Superior que atuam em cursos de Licenciatura. Aplicamos a proposta durante o ano de 2015 e 2016.1 em turmas do curso de Licenciatura em Ciências Biológicas do Centro Acadêmico de Vitória, de forma que foi possível testar modelos de atuação docente, na perspectiva da orquestração, além do uso de algumas ferramentas e artefatos digitais nessa orquestração. Desta forma, a presente pesquisa tem um caráter metodológico exploratório de intervenção e o desenvolvimento da mesma seguiu os seguintes passos: (i) sondagem e ambientação; (ii) empoderamento e cooperação; (iii) ações orquestradas.

\subsection{Sondagem e ambientação:}

Antes de iniciar o semestre em si, vimos a necessidade de desenvolver uma sondagem com os alunos, a fim de identificar perspectivas e expectativas quanto aos conteúdos da disciplina, além de seus hábitos tecnológicos, para devida seleção dos recursos mais eficazes aos objetivos de aprendizagem previamente vislumbrados.

Foi elaborado um questionário, disponibilizando-o no e-mail da turma, assim como no grupo criado por eles mesmos na rede social Facebook $k_{\circledast}$. Nesta sondagem, dentre outras informações, foi revelado que $100 \%$ dos alunos possuíam smartphones e acesso a Internet em casa, o que facilitava algumas atividades a distância; que $100 \%$ eram usuários do Facebook e em menor escala participavam de outras redes sociais também. Cerca de $65 \%$ dos alunos possuíam acesso a Internet $3 \mathrm{G}$ ou $4 \mathrm{G}$, o que possibilitou interações na própria sala de forma bem consistente. Inclusive este foi um dos critérios que permitiu a organização dos grupos de trabalhos (GTs), estabelecendo que sempre houvesse 3 ou 4 alunos com acesso a conexão $3 \mathrm{G}$ ou $4 \mathrm{G}$ em cada GT para as atividades em sala de aula, uma vez que nem sempre contávamos com a estabilidade da rede WiFi da Instituição.

A ambientação se deu na apresentação e devidos esclarecimento sobre a dinâmica de como foi preparado o planejamento das atividades didáticas do semestre, as formas e instrumentos e critérios de avaliação [Luckesi 2994], o qual indica um 
caminho pela avaliação responsiva que permita clareza sobre o que se espera do processo e das produções.

Os GTs se organizavam para desenvolver os desafios propostos, a partir de conversas, estudos e diálogo com os pares e com o professor sobre possibilidades de trabalho de conteúdos e métodos específicos, pela rede social. Neste momento estabeleceu-se o processo mais ativo da mediação do professor [Moran et al 2006], colaborando no esclarecimento dos conteúdos e se integrando a cada um dos GTs. Aqui a orquestração se deu a partir da checagem das postagens no Grupo do Facebook, permitindo intervenção textual e acompanhamento processual antes da aula da semana seguinte iniciar.

Desta forma, as interações espaço-tempo puderam ser mais duradoras e criaram um registro histórico que também serviu como artefato de orquestração, uma vez que possibilitou ao professor perceber detalhes, dúvidas que eventualmente não surgiriam em sala devido à dinâmica mais coletiva que esse espaço propõe. Pudemos vivenciar o que Levy (1999) afirma sobre o leque de interação existente no ciberespaço, como interação um-um, um-todos, todos-todos. Nesta dinâmica foi possível ampliar as possibilidades comunicacionais e relacionais entre os sujeitos envolvidos no processo.

\subsection{Empoderamento e cooperação}

Considerando a necessidade de integrar os alunos ao seu próprio processo de construção do conhecimento, comungamos com a ideia de autonomia já propagada por autores como Berbel (2011), Ryan and Conell (1989) e DeCharms (1976). A ideia de autonomia defendida por estes autores indica que a autoderminação do sujeito sofre influências de meios externos, da sua interação com os outros, de contextos específicos e impacta a sua própria forma de se ver e se perceber frente a determinados desafios. Ou seja, os interesses do sujeito emergirão de forma a estimulá-lo à execução de atividades, considerando que esta não lhe apresente como uma imposição externa, alheia a sua compreensão.

Assim, o trabalho cooperativo, no qual os alunos são empoderados sobre sua própria formação, alcança o limiar da intencionalidade do aluno em querer se formar da melhor maneira possível, de forma a ativar sua autodeterminação e assim atingir os objetivos necessários para a conclusão de mais uma disciplina.

O fato de envolver os alunos no planejamento dos conteúdos e métodos de condução de cada aula possibilita um clima de colaboração contínuo na turma e resulta, como foi percebido no processo de orquestração, que houve mobilização de aderência por parte de alguns alunos que tenderiam a desmotivação. Em conversa com dois desses alunos constatamos que eles aderiram mais ao processo a fim de não mostrarem aos colegas e ao professor suas desmotivações, desinteresses e limitações.

O processo de orquestração, no que tange a tomada de consciência e gerenciamento do fluxo, possibilitou ao professor a ação mediadora nesse momento inicial onde se contextualizou os procedimentos da dinâmica de planejamento, e orientou-se para a organização da turma em pequenos grupos de trabalhos GTs. Tais grupos foram formados espontaneamente pelos alunos, já partindo da premissa de estímulo a autonomia. Contabilizaram, avaliaram os grupos por afinidade e começaram suas produções. 
As orientações aos GTs perpassaram por duas ações concomitantes: (i) trabalhos específicos de cada GT e (ii) trabalhos coletivos que envolveu toda a turma. Assim os grupos estudaram antecipadamente os conteúdos, tiraram dúvidas com o professor e monitores da disciplina e elaboraram seus planos de aulas, sempre em diálogo com o professor, de forma a refinar possíveis arestas que os alunos não tenham percebido.

Os GTs então definiram os objetivos para seus projetos de aulas, além de um cronograma de execução, o qual esteve em harmonia com o calendário acadêmico da IE. Tal calendário foi entregue em modelo de planilha eletrônica online (Google Drive) para cada GT alinhar de forma compartilhada um único cronograma, uma vez que as atividades envolveram uma mesma disciplina e a mesma turma. No cronograma já foram dispostos os eventos internos do curso, surgindo como um desafio para que os GTs alinhassem uma sequência didática que contemplasse estes eventos.

\subsection{Ações orquestradas}

De acordo com Dillembourg (2013, p. 02), a orquestração se refere "a como um professor consegue, em tempo real, gerenciar atividades multicamadas em um contexto de multirrestrições" (tradução nossa). Para que este gerenciamento aconteça é necessário que o professor manipule diferentes ferramentas (simulações, testes, wikis, etc.), entendendo aqui estas ferramentas enquanto atividades a serem desenvolvidas pelos alunos. Estas ferramentas podem ser desenvolvidas com apoio de artefatos digitais (laptops, tablets, sensores, smartphones, etc) em meio a dinâmicas de aplicação colaborativa e também individuais.

Partindo desta premissa teórica, e em meio a uma variedade de atividades propostas pelos próprios alunos, entendemos que precisamos lançar mão de artefatos que possibilitem o controle dessas ações. Controle aqui é entendido enquanto uma posição do cuidado e articulação de todo um processo. A autonomia dos alunos é constantemente estimulada a fim de desenvolver o poder criativo deles, bem como a tomada de consciência sobre os aspectos que estão estudando e desenvolvendo, na complexidade que isso tudo envolve, tanto em relação ao conhecimento a ser construído, como também no possível impacto social, político e ético.

Os artefatos que utilizamos foi o Evernote - bloco de anotações que permite inserção de arquivos de áudio, vídeo e links, de forma que possa ser compartilhado com outros usuários deste aplicativo, que pode ser executado em múltiplas plataformas. Este caderno compartilhado do Evernote permitiu ao professor acompanhar em tempo real as anotações dos alunos, através das notas feitas em um caderno compartilhado com o professor. A partir desta visão imediata do que estavam produzindo foi possível fazer intervenções para o bom andamento da aprendizagem dos objetivos previamente estabelecidos.

Outro artefato usado - mapa canvas - não é digital e se adéqua a nossa proposta de uso de técnicas de design thinking. Este canvas é usado com adesivos do tipo post-it ${ }_{\circledast}$ coloridos e registra ações dos alunos em um mapa de planejamento que é fotografado e compartilhado com toda a turma na rede social. O uso de post-it ${ }_{\circledast}$ para preenchimento dos campos do canvas de planejamento [Gomes e Silva, 2016] é útil no sentido de promover uma dinâmica não fixa do planejamento. Os alunos podem editar seu mapa sempre que uma nova ideia surge e ir atualizando a imagem para o grupo na rede social. 
V Congresso Brasileiro de Informática na Educação (CBIE 2016)

Anais dos Workshops do V Congresso Brasileiro de Informática na Educação (CBIE 2016)

A orquestração aqui se dá no sentido de compreender a visão de progresso dos alunos e a coesão entre o que falam e o que registram em seus planos.

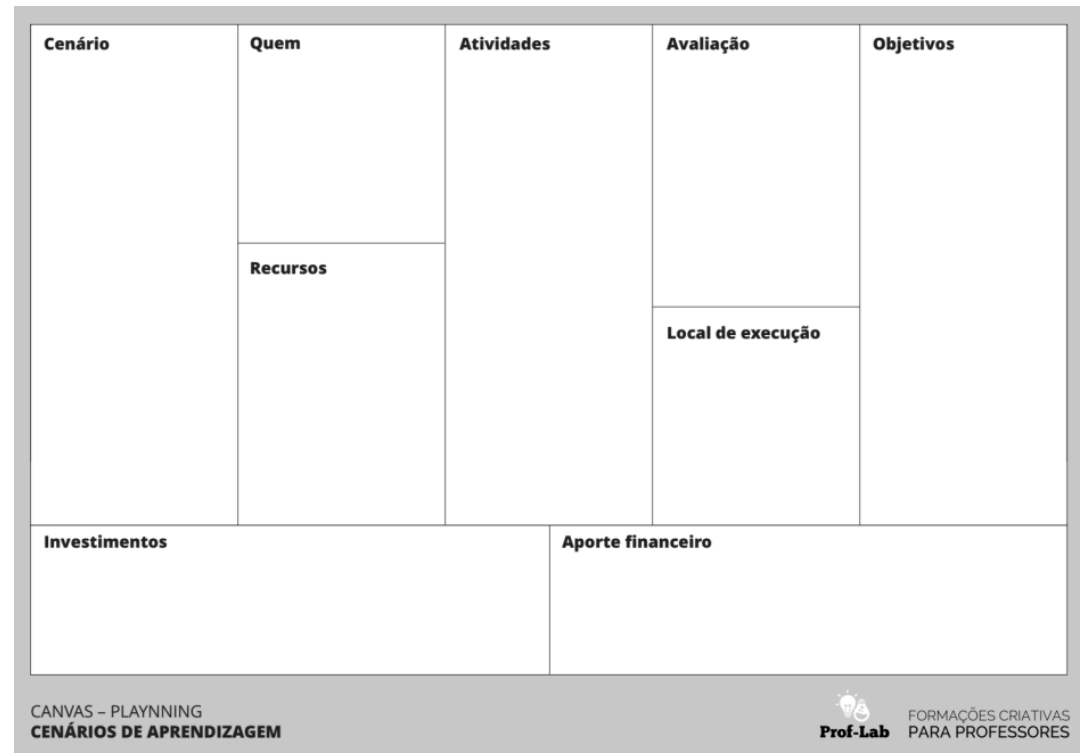

Figura 1. Mapa canvas de planejamento [Gomes e Silva 2016]

Outros artefatos usados na aula vieram das próprias propostas desenvolvidas pelos alunos. Tais artefatos foram inseridos de forma a possibilitar o dinamismo que a aula exige, porém não se perdendo de vista a orquestração da aula, a possibilidade de intervenção promovida pela visualização, pelo "alerta" in time que o artefato ou a ferramenta usada para a atividade gerasse para a ação do professor.

A exemplo disto citamos aqui o uso do mapa conceitual (ferramenta), construído através do aplicativo CmapTools ${ }_{\circledast}$ com apoio de um laptop (artefato), o mapa foi projetado no quadro e sua construção ia se dando através de sugestões dos alunos. Um aluno operava o aplicativo no momento. Neste instante era possível monitorar a ação dos alunos. Os mapas que iam sendo construídos nos pequenos grupos (trios ou duplas), iam "nutrindo" o mapa principal da turma. O passeio do professor pela sala neste momento possibilitava uma visão rápida sobre o andamento da construção dos mapas, percebendo quem necessitava de intervenção de facilitação do processo. O mapa conceitual coletivo construído foi partilhado no formato de imagem no caderno do Evernote, assim como os demais mapas.

Dillembourg (2013) afirma que as variáveis que envolvem a orquestração abrangem aspectos intrínsecos e extrínsecos, necessitando de uma constante integração pedagógica a partir da integração técnica de diferentes ferramentas com diferentes artefatos para desenvolvimento das atividades. Desta forma o professor assume o papel de mediação do processo de ensino-aprendizagem de forma mais factível do que um discurso de mediação na qual o professor, muitas vezes, não sabe com precisão o que os alunos estão desenvolvendo, descobrindo isto apenas no final do processo, quando em momento didático de exposição da atividade solicitada. 
V Congresso Brasileiro de Informática na Educação (CBIE 2016)

Anais dos Workshops do V Congresso Brasileiro de Informática na Educação (CBIE 2016)

\section{Considerações Finais}

Com a aplicação podemos constatar que o envolvimento dos alunos enquanto autores dos seus próprios processos de aprendizagem tornam o engajamento nas aulas muito mais efetivo. Além de termos um índice de presença nas aulas de cerca de $95 \%$ dos alunos em todas as aulas, percebemos a participação ativa dos mesmos na execução das atividades, uma vez que se empoderam do processo e sentem-se mais confiantes em relação ao que precisam e querem aprender. Este aspecto é apresentando pelas perguntas pertinentes que emergem a cada conteúdo trabalhado, nas atividades que eles mesmos propuseram, nos Canvas de Planejamento construídos, e nos registros no Evenrote $_{\circledast}$.

A avaliação formativa empregada, deixa claro para a turma todos os critérios que se pretendia verificar a partir da ação de mediação durante as aulas, de forma que essa postura gerasse segurança e objetividade por parte dos alunos na execução das atividades.

Os indicadores de aproveitamento da turma revelam que as experiências de aprendizagem vivenciadas pelos alunos são positivas, uma vez que obtivemos produções que atingiram os objetivos propostos. Outro indicador é o despertar de alguns alunos para publicação das suas experiências em Congressos locais. Outro fator que se destaca é a valorização da forma prática de estudar em sala, em especial quando em contato com recursos tecnológicos, saindo da "mesmice" de quadro e exposição oral em suas experiências de aulas. Por fim, entendemos que um fator secundário mas não menos importante foi o favorecimento e ampliação comunicacional entre alunos e professor.

Fica o desafio de se explorar aspectos mais específicos da aprendizagem dos alunos e os impactos deste tipo de metodologia para a formação do sujeito para além das dimensões específicas da disciplina proposta nesta pesquisa. Na perspectiva dos nossos objetivos quanto a orquestração da aula, obtivemos melhores respostas dos alunos na relação com as propostas que foram vivenciadas no semestre. Além de poder usar os recursos tecnológicos empregados para auxiliar no processo de mediação e avaliação.

Nossa contribuição recai sobre o impacto na formação inicial do professor para um contexto cultural em que o digital se faz presente na rotina diária e que precisa ser assimilado para e nas ações dentro das Instituições de Ensino, sejam básica ou superior. Além disso, um projeto de pesquisa formação está em andamento no sentido de investigar práticas de orquestração com professores de licenciaturas de diferentes áreas - linguagem, matemática, saúde, ciências sociais e pedagogia - após período de formação inicial e mentoreio de processo, a fim de identificar entraves e avanços para essa visão do fazer pedagógico orquestrado no ensino superior. 
V Congresso Brasileiro de Informática na Educação (CBIE 2016)

Anais dos Workshops do V Congresso Brasileiro de Informática na Educação (CBIE 2016)

\section{Referências}

Berbel, Neusi Aparecida Navas (2011). "As metodologias ativas e a promoção da autonomia de estudantes”. Semina: Ciências Sociais e Humanas, Londrina, v. 32, n.1, p. 25-40, jan./jun. 2011.

Dimitriadis, Y. A. Supporting teachers in orchestrating CSCL classrooms. (2010). A. Jimoyiannis (ed.), Proceedings of the " $7^{\text {th }}$ Pan-Hellenic Conference with International Participation «ICT in Education»", vol.I, pp.33-40. University of Peloponnese, Korinthos, Greece, 23-26.

Dillenbourg, P. (2013). "Design for classroom orchestration". Computers \& Education 69 p.485-492. Disponível em <http://www.sciencedirect.com/science/article/pii/S0360131513001061> Acesso em junho/2015.

DeCharms, R. (1976). "Enhancing motivation:" Change in the classroom. New York: Irvington.

Fischer, F.; Dillenbourg, P. (2006) "Challenges of orchestrating computer-supported collaborative learning". Paper Presented at the $87^{\text {Th }}$ Annual Meeting of the American Educational Research Association (AERA).

Freire, P. (2000). "Pedagogia da Indignação": cartas pedagógicas e outros escritos. São Paulo: Editora UNESP.

Gomes, A.S; Silva, P.A. (2016). "Planejamento de experiências de aprendizagem": criatividade e inovação para o planejamento de aulas. Recife: Pipa Comunicação. Vol. 3.

Kerckhove, D. (2003) "A arquitetura da inteligência: interfaces do corpo, da mente e do mundo". In Arte e vida no século XXI - tecnologia, ciência e criatividade, Edited by D. Domingues. São Paulo: Editora UNESP, p.15-26

Levy, P. (1999). “Cibercultura”. São Paulo: Editora 34.

Moran, J.M.; Masetto, M.T.; Behrens, M.A. (2006). "Novas tecnologias e mediação pedagógica". $10^{\mathrm{a}}$ ed. Campinas: Papirus.

Prieto, L.P. (2010) "The many faces of orchestration": Towards a (more) operative definition, Unpublished Technical Report, University of Valladolid, Spain. Disponível em: <http://www.mendeley.com/research/faces-orchestration-towardsmore-operative-definition/> Acesso em julho/2014.

Ryan, R.M. and Conell, J.P. (1989) "Perceived Locus of Causality and Internalization": Examining Reasons for Acting in Two Domains. Journal of Personality and Social Psychology, VoL57, No 5, 749-761. Copyright by the Ameriean Psyehologieal Assoeiation.

Vianna, M.; Vianna, Y.; Adler, I.K.; Lucena, B; Russo, B. (2012). "Design Thinking:" Inovação em Negócios. Rio de janeiro: MJV Press.

Vygotsky, L. S. (1984) “A Formação Social da Mente”. São Paulo: Martins Fontes. 